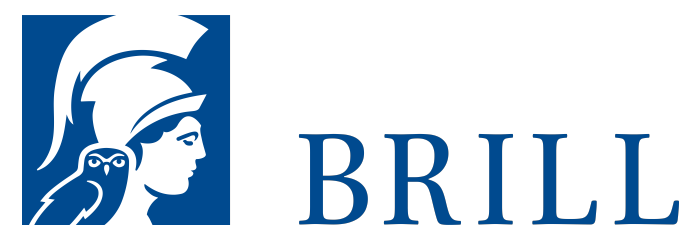

\title{
Sapphostudien zu ausgewählten Fragmenten
}

Teil 1 und 2

Author: Luca Benelli

Die Nordrhein-Westfälische Akademie der Wissenschaften und der Künste ist eine Vereinigung der führenden Forscherinnen und Forscher des Landes. Sie wurde 1970 als

Nachfolgeeinrichtung der Arbeitsgemeinschaft für Forschung des Landes Nordrhein-Westfalen gegründet. Die Akademie ist in drei wissenschaftliche Klassen für Geisteswissenschaften, für Naturwissenschaften und Medizin sowie für Ingenieur- und Wirtschaftswissenschaften und in eine Klasse der Künste gegliedert.

Mit Publikationen zu den wissenschaftlichen Vorträgen in den Klassensitzungen, zu öffentlichen Veranstaltungen und Symposien will die Akademie die Fach- und allgemeine Öffentlichkeit über die Arbeiten der Akademie und ihrer Forschungsstellen informieren.

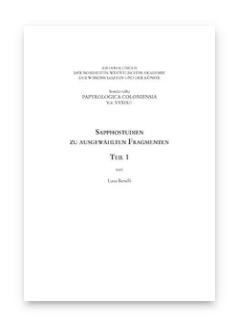

Pages: XXII +

555 Seiten

Language:

German

Subjects:

Ancient History,

Classical Studies

Publisher: Brill |

Schöningh

Series:

Sonderreihe der

Abhandlungen

Papyrologica

Coloniensia,

Volume: 39

E-Book (PDF)

Released online:

22 Jun 2020

ISBN: 978-3-

657-78839-2

List price

Paperback

Publication date: o8 Sep 2017

ISBN: $978-3^{-}$

506-78839-9

List price 
For more information see brill.com

Order information: Order online at brill.com +44330 333 0049 | customerservices@brill.com Submission information: brill.com/authors

Titles published by Brill | Fink, Brill | mentis or Brill | Schöningh: +49(o)715413279216| brill@brocom.de 